\title{
Understanding hyperlipidemia and atherosclerosis: lessons from genetically modified apoe and IdIr mice
}

Citation for published version (APA):

Wouters, K. A. M., Shiri-Sverdlov, R., van Gorp, P. J. J., van Bilsen, M., \& Hofker, M. H. (2005).

Understanding hyperlipidemia and atherosclerosis: lessons from genetically modified apoe and Idlr mice. Clinical Chemistry and Laboratory Medicine, 43(5), 470-479. https://doi.org/10.1515/CCLM.2005.085

Document status and date:

Published: 01/01/2005

DOI:

10.1515/CCLM.2005.085

Document Version:

Publisher's PDF, also known as Version of record

Document license:

Taverne

Please check the document version of this publication:

- A submitted manuscript is the version of the article upon submission and before peer-review. There can be important differences between the submitted version and the official published version of record.

People interested in the research are advised to contact the author for the final version of the publication, or visit the DOI to the publisher's website.

- The final author version and the galley proof are versions of the publication after peer review.

- The final published version features the final layout of the paper including the volume, issue and page numbers.

Link to publication

\footnotetext{
General rights rights.

- You may freely distribute the URL identifying the publication in the public portal. please follow below link for the End User Agreement:

www.umlib.nl/taverne-license

Take down policy

If you believe that this document breaches copyright please contact us at:

repository@maastrichtuniversity.nl

providing details and we will investigate your claim.
}

Copyright and moral rights for the publications made accessible in the public portal are retained by the authors and/or other copyright owners and it is a condition of accessing publications that users recognise and abide by the legal requirements associated with these

- Users may download and print one copy of any publication from the public portal for the purpose of private study or research.

- You may not further distribute the material or use it for any profit-making activity or commercial gain

If the publication is distributed under the terms of Article $25 \mathrm{fa}$ of the Dutch Copyright Act, indicated by the "Taverne" license above, 


\section{Understanding hyperlipidemia and atherosclerosis: lessons from genetically modified apoe and IdIr mice ${ }^{1)}$}

\author{
Kristiaan Wouters 1,*, Ronit Shiri-Sverdlov ${ }^{1, *}$, \\ Patrick J. van Gorp', Marc van Bilsen² and \\ Marten H. Hofker ${ }^{1, * *}$ \\ ${ }^{1}$ Department of Molecular Genetics, \\ ${ }^{2}$ Department of Physiology, \\ Universiteit Maastricht, Maastricht, The Netherlands
}

\begin{abstract}
Hyperlipidemia is the most important risk factor for atherosclerosis, which is the major cause of cardiovascular disease. The etiology of hyperlipidemia and atherosclerosis is complex and governed by multiple interacting genes. However, mutations in two genes have been shown to be directly involved, i.e., the lowdensity lipoprotein receptor (LDLR) and apolipoprotein $\mathrm{E}$ (ApoE). Genetically modified mouse models have been instrumental in elucidating the underlying molecular mechanisms in lipid metabolism. In this review, we focus on the use of two of the most widely used mouse models, ApoE- and LDLR-deficient mice. After almost a decade of applications, it is clear that each model has unique strengths and drawbacks when carrying out studies of the role of additional genes and environmental factors such as nutrition and lipid-lowering drugs. Importantly, we elaborate on mice expressing mutant forms of $A P O E$, including the APOE3Leiden (APOE3L) and the APOE2 knock-in (APOE2k) mouse models. These models have outstanding potential, as they are highly responsive to dietary factors and pharmacological interventions.
\end{abstract}

Keywords: apolipoprotein E (ApoE); gene targeting; genetics; genomics; hyperlipoproteinemia; low-density protein receptor (LDLR); transgenesis.

\section{Introduction}

Atherosclerosis is the major cause of cardiovascular disease (CVD) and is a complex condition caused by various genetic and environmental factors. It has

\footnotetext{
1) This article is based on a contribution made at the 2nd Santorini Prospective Conference 2004 "From Human Genetic Variations to Prediction of Risks and Responses to Drugs and to the Environment", Santorini, Greece, Sep 30-Oct 4, 2004. * Both authors contributed equally to this paper.

**Corresponding author: Marten H. Hofker, Cardiovascular Research Institute Maastricht, Department of Molecular Genetics, Universiteit Maastricht UNS50/11, P.O. Box 616 6200MD Maastricht, The Netherlands

Phone: +31-43-388-1138, Fax: +31-43-388-4574,

E-mail:m.hofker@gen.unimaas.nl
}

proved to be very difficult to identify the hereditary factors responsible. Susceptibility to CVD varies among individuals because the genetic component is the result of complex interactions among many genes. Only in rare cases do single gene mutations lead to atherosclerosis, often in genes with key roles in lipid homeostasis. The best-known examples are the genes encoding the low-density lipoprotein receptor (LDLR) and apolipoprotein E (ApoE). In the early 1980s, the discovery of mutations within these genes initiated a major effort to scrutinize the entire set of lipid genes for mutations. A more recent example includes the discovery of the role of the $A B C A 1$ gene in Tangiers disease, a heritable deficiency of highdensity lipoproteins (HDLs).

Despite the large number of genes linked to lipid disorders, it is still difficult to explain common mild hyperlipidemias at the genetic and molecular levels, and genes associated with atherosclerosis are even more difficult to identify via human genetic studies.

At present, however, research on mouse models for atherosclerosis is providing crucial insights into the role of additional genes and environmental factors. Unfortunately, the wild-type mouse is quite resistant to CVD, due to high levels of anti-atherogenic HDL and low levels of pro-atherogenic lipoproteins, i.e., very-low-density lipoprotein (VLDL) and LDL. The use of mouse models in the cardiovascular field, however, only became feasible when technologies capable of generating transgenic and knockout mice became generally available. The most widely used mouse models were developed using the $I d / r$ and apoe genes. By using these mice as sensitized background strains, it became possible to investigate the role of additional genes, diets and other environmental factors.

First, we introduce the human hyperlipidemias caused by mutations in the Idlr and apoe genes. Second, we describe the models based on these mutations, and finally we delineate how these models are instrumental in further delineating dyslipidemias and atherosclerosis.

\section{Lipoprotein disorders}

The most common genetic hyperlipidemic disorder is type II hyperlipoproteinemia (type II HLP), also referred to as familial hypercholesterolemia (FH), which is characterized by elevated plasma LDL levels. $\mathrm{FH}$ patients suffer from yellowish lipid deposits in the skin and subcutaneous tissue, called xanthomas. Xanthoma tuberosum and tendinosum are characteristic 


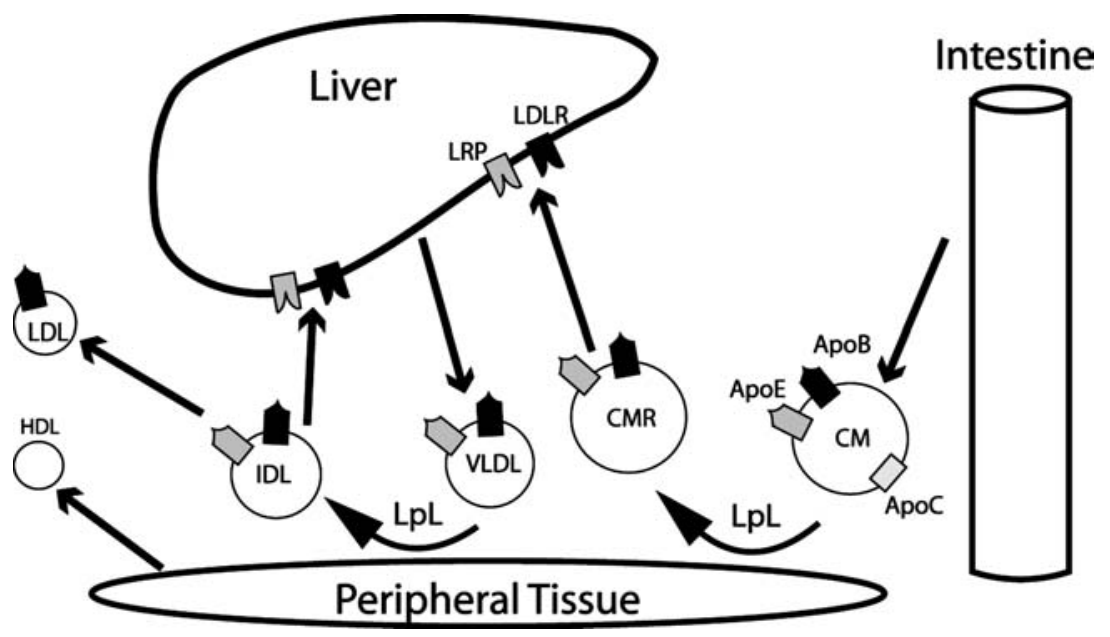

Figure 1 Major functions of ApoE. Triglycerides (TGs), cholesterol and other lipids are packaged into chylomicrons (CMs) after digestion and absorption in the intestine. CMs contain the apolipoproteins ApoB, ApoC and ApoE. The CMs enter the circulation, where their TGs are hydrolyzed by $\mathrm{LpL}$, which can be modulated by ApoE. The resulting CM remnants (CMRs) are rapidly taken up by the liver through the binding of ApoE to the LDLR and the LRP. ApoE can also stimulate VLDL production in and secretion out of the liver. Circulating VLDL particles, which contain ApoE and ApoB, also undergo lipolysis, turning them into VLDL remnants or IDL. IDLs are internalized by the liver through binding to the LDLR and LRP, which means that this process is also dependent on ApoE. Further lipolysis of remaining IDLs results in LDL. These lipoproteins can be taken up by the LDLR through binding with the ApoB particles present in LDLs. ApoE can also modulate cholesterol efflux out of the peripheral tissues to small circulating HDL.

of $\mathrm{FH}$ (1). These patients are also at higher risk of developing atherosclerosis. One of several types of $\mathrm{FH}$ is a monogenic form, with a frequency of 1 in 500 individuals. This form is caused by defects in the gene coding for the LDLR, resulting in defective clearance of LDL from the plasma. Consequently, this lipoprotein, containing large amounts of cholesterol, accumulates in the circulation (2).

Type III hyperlipidemia represents a rarer condition than $\mathrm{FH}$, with a frequency of 1-4 in 10,000 individuals in the Caucasian population. The cause of this abnormality is either ApoE deficiency or a defective form of ApoE that cannot fully bind to the receptor. This malfunctioning ApoE also has variable binding capacities to heparin sulfate proteoglycans (HSPGs), needed for uptake via the LDLR-related protein (LRP)-mediated secretion-recapture process (3-5). This is hallmarked by an accumulation of chylomicron remnants (CMRs), which originate from intestine-derived lipoproteins, and VLDL remnants (VLDLRs), originating from liverderived VLDL. These lipoprotein remnants are collectively called $\beta$-VLDL. The disorder is therefore also called familial dysbetalipoproteinemia (FD) $(3,6)$. FD patients have elevated levels of triglycerides and total cholesterol in the plasma and also suffer from xanthomas, mainly palmar crease xanthoma, which is indicative of this condition $(1,3)$. Similar to $\mathrm{FH}$, type III HLP patients have increased susceptibility to atherosclerosis.

ApoE was initially found to be a component of VLDL (7) and later of the type III hyperlipidemia-associated $\beta$-VLDL as well (8). VLDL and $\beta$-VLDL were shown to have far higher affinity for the LDL receptor than LDL itself, which contains ApoB instead of ApoE (9). ApoE thus serves for the clearance of chylomicrons and VLDL from the plasma. Several other functions of
ApoE have also been described. It is a ligand for hepatic clearance via the $\operatorname{LRP}(10,11)$, it modulates lipoprotein lipase (LpL) activity, presumably by masking APOCII, an activator of $\operatorname{LLL}(12,13)$. Furthermore, it can stimulate VLDL production in the liver $(12,14)$ in an isoform-specific manner (15) and modulate cholesterol efflux from different cells and tissues $(16,17)$ (Figure 1). Therefore, it is clear that any malfunctioning of the ApoE protein could have drastic consequences for lipoprotein metabolism.

The most common cause of FD is homozygosity of the allele for the ApoE2 isoform. APOE2 has a gene frequency of $10 \%$ in the human population. It contains a cystein instead of an arginine at residue 158 (3). Due to this mutation, ApoE has lost more than $99 \%$ of its binding capacity to its receptor compared to ApoE3, the common isoform. It is proposed that ApoE2 is associated with a recessive mode of inheritance. Most isoforms are preferentially confined to the VLDL fraction, whereas the ApoE2 isoform seems to be present to a greater degree in HDL. If ApoE2 and the common isoform were present in plasma at equal levels (heterozygosity), ApoE2 would preferentially associate with HDL, leading to VLDLs containing mostly normal ApoE3 and making them more suitable for clearance from the blood [reviewed by Mahley, Huang and Rall (18)]. Nevertheless, a very small percentage $(5 \%)$ of homozygote individuals will eventually develop FD. This probably means that, due to the low penetrance of FD, other genes and environmental factors have a modulatory effect on this disorder.

Other defective ApoE isoforms lead to a dominant pattern of inheritance, but are rarer. An example of this is the ApoE3Leiden (ApoE3L) isoform, which has an extra 7-amino-acid tandem repeat sequence at residues 121-127. This leads to a conformational 
change in the protein that prevents adequate binding to hepatic receptors (19).

There are also several other lipoprotein disorders besides these two diseases, including type I, type IV and type $\mathrm{V}$ hyperlipoproteinemia. Some risk factors for these conditions are very well known, such as LpL and ApoCll deficiency, while others remain to be found.

\section{The use of hyperlipidemic mouse models in cardiovascular research}

Using mice in atherosclerosis research has many advantages, such as easy handling, short generation span and large litter size. On the other hand, differences between mice and humans in terms of susceptibility to atherosclerosis, lipoprotein metabolism and plaque morphology have to be appreciated.

Normally, mice are resistant to atherosclerosis, but Paigen et al. (20) demonstrated a huge variation in atherosclerosis formation in 10 different inbred mice strains upon feeding a pro-atherogenic diet. Due to this diet, the mice all developed hyperlipidemia, although the formation of atherosclerosis differed enormously between the different inbred strains with no correlation with plasma lipid levels. The C57BL/6J strain appeared to be most susceptible to atherosclerotic lesion formation. Despite the large amount of cholesterol (1.25\%) and the presence of (sodium) cholate $(0.5 \%)$ in the atherogenic diet, these mice showed very simple and small lesions, mainly consisting of lipid-laden macrophages, also called foam cells. This plaque morphology did not resemble the advanced human plaque, which consists of altered endothelial cells, foam cells and proliferating smooth muscle cells that form fibrous tissue. This fibrous tissue forms a fibrotic cap that overlies a core of lipid and necrotic tissue. Eventually, the fibrotic cap may rupture, which can cause thrombosis, thus leading to an acute coronary event and/or stroke $(21,22)$.

The Paigen diet (20) was determined to be nonphysiological (23) and it has been demonstrated that the high cholesterol and the addition of cholate in the atherogenic diet causes an inflammatory response in the liver and other tissues, possibly arteries $(24,25)$. Atherosclerosis is increasingly known as a disease in which inflammation plays a major role in its development (21), so use of the pro-inflammatory cholatecontaining diet is controversial. Moreover, the application of the mouse in atherosclerosis research remained limited.

This situation changed dramatically when genetically modified animals were generated lacking certain genes important for lipid metabolism, such as apoe knock-out $\left(a p o e^{-/-}\right)$and $/ d l r$ knock-out $\left(/ d / r^{-/-}\right)$mice $(26,27)$. Other mice were created with human genes inserted into the mouse genome, e.g., the transgenic APOE3Leiden mouse (28). It also became possible to specifically replace mouse genes with their human counterparts, such as the APOE2 knock-in mouse (29). The properties and application of these mouse models are discussed below. Table 1 shows a short overview of the cholesterol distributions in the lipoprotein factions of these mice.

\section{apoe $^{-/-}$mouse model}

A mouse deficient for the apoe gene was created in different laboratories $(26,27)$. On a normal chow diet, these animals display plasma cholesterol levels of at least five-fold more than their wild-type counterparts. When given a high-fat diet mildly elevated in cholesterol without added cholate, the mice had even a further three-fold rise. Triglycerides were lowered to half of the level that was observed in chow-fed animals (26). A high-fat diet containing higher amounts of cho-

Table 1 Cholesterol distribution in lipoprotein fractions of different mouse models.

\begin{tabular}{|c|c|c|c|c|c|}
\hline Model & Fraction & Mutant vs. WT & WTD vs. chow & HFC vs. chow & References \\
\hline \multirow[t]{3}{*}{ apoe $e^{-/-}$} & VLDL & $\uparrow \uparrow \uparrow$ & $\uparrow \uparrow$ & $\uparrow \uparrow \uparrow$ & \multirow[t]{3}{*}{$(26,27,30)$} \\
\hline & LDL & $\uparrow \uparrow$ & $\uparrow$ & $\uparrow \uparrow$ & \\
\hline & HDL & $\downarrow$ & No change & $\uparrow \uparrow$ & \\
\hline \multirow[t]{3}{*}{$|d| r^{-/-}$} & VLDL & $\uparrow$ & $\uparrow$ & $\uparrow \uparrow$ & \multirow[t]{3}{*}{ (31) } \\
\hline & LDL & $\uparrow \uparrow$ & $\uparrow \uparrow$ & $\uparrow \uparrow$ & \\
\hline & HDL & $\uparrow$ & No change & $\downarrow$ & \\
\hline \multirow[t]{3}{*}{ APOE3L } & VLDL & $\uparrow$ & $\uparrow^{1}$ & $\uparrow \uparrow$ & \multirow[t]{3}{*}{$(32)$} \\
\hline & LDL & $\uparrow$ & $\uparrow \uparrow^{1}$ & $\uparrow \uparrow$ & \\
\hline & HDL & $\downarrow$ & $\uparrow^{1}$ & $\uparrow \uparrow$ & \\
\hline \multirow[t]{3}{*}{ APOE2ki } & VLDL & $\uparrow \uparrow \uparrow$ & $\uparrow \uparrow^{2}$ & - & \multirow[t]{3}{*}{$(29,33)$} \\
\hline & LDL & $\uparrow \uparrow$ & $\uparrow^{2}$ & - & \\
\hline & HDL & No change & No change ${ }^{2}$ & - & \\
\hline
\end{tabular}

The Table shows relative changes in cholesterol levels in different lipoprotein fractions of the genetically altered mouse models. Mutant vs. WT indicates the levels in the mouse model when fed a normal chow diet compared to a wild-type (WT) mouse on a chow diet. WTD vs. chow and HFC vs. chow indicate cholesterol levels of the mouse model on a certain diet compared to cholesterol levels of that mouse model on a normal chow diet. WTD, Western type diet containing various amounts of saturated fat and cholesterol; HFC, high-fat diet containing various amounts of saturated fat and cholesterol and cholate (pro-atherogenic diet). Arrows indicate the relative increase or decrease for the specific mouse models on specific diets: $\uparrow$, small rise; $\uparrow \uparrow$, considerable rise; $\uparrow \uparrow \uparrow$, extreme rise. ${ }^{1}$ Diet contained a minimal amount of cholate (0.1\%). ${ }^{2}$ Only data from male mice. 
lesterol and cholate resulted in a very large increase in cholesterol levels, while triglyceride levels did not change $(27,30)$. Cholesterol was mainly found in VLDL/intermediate density lipoprotein (IDL) fractions in apoe ${ }^{-/-}$mice fed chow and high-fat diets, and to a lesser extent in the LDL fraction of these animals (Table 1). This lipid distribution resembles the lipid profiles found in type III hyperlipidemia patients, although the composition of VLDL particles differs dramatically $(4,6)$. Even heterozygous expression of the apoe gene caused hyperlipidemia (34).

Spontaneous plaque formation was found in these animals (27) but, in line with their enormous response to high-fat feeding, it is possible to induce accelerated and more severe atherosclerotic plaque formation in many vascular areas when given a high-fat diet (26, $28,30)$. Lesions consisted of foam cells and a lipidcontaining necrotic core. A proliferative cellular response was found in the vessel wall, as well as a fibrous cap (26). Accordingly, the lesions closely resemble advanced human plaques, and therefore the availability of the apoe ${ }^{-/-}$mouse can be considered an important landmark in the use of mouse models to study atherosclerosis.

Due to these responses upon high-fat feeding, the apoe $e^{-/-}$mouse has become the most widely used mouse model for hyperlipidemia and atherosclerosis. This model is therefore particularly useful as a sensitized strain to investigate the role of additional genes. In particular, insights can be obtained into the role of genes that are unrelated to lipid metabolism. Such genes are crucial for study in the absence of models for very severe diets, and in those cases the apoe ${ }^{-1-}$ model is the preferred alternative. Using this strategy, various genes that are implicated in atherogenesis, ranging from genes related to inflammation, hyperglycemia, hypertension and coagulation, have been identified [for a review see (35)].

Mice carrying "candidate genes" that are suspected of being involved in atherogenesis can be crossed with $a p o e^{-1-}$ mice. These crosses may lead to a better understanding of the role of such specific mutations in atherosclerosis. Unfortunately, when using such crosses between transgenic mice, study is confined to those candidate genes. It is also possible to follow an unbiased approach using mouse genetics. By carrying out a series of crosses between mice, several quantitative trait loci (OTL) can be found. In this manner, several loci on the mouse genome have been identified as carrying genes likely to be involved in the pathology of atherogenesis $(36,37)$.

The clinical relevance to human atherosclerosis remained questionable, since common clinical events such as plaque rupture and thrombosis could not be identified until these events were found in the innominate artery quite recently by Rosenfeld et al. (38). As reviewed by Cullen et al. (39), a few more mouse models of plaque rupture emerged; however, these models are still rather controversial. The site specificity of atherosclerotic plaques also remains the subject of debate. Probably due to differences in blood flow, specific parts of the vasculature are more prone to atherosclerosis. Therefore, it is possible that plaque formation at some sites in the mouse arterial tree is more relevant to human atherogenesis than others. However, up until recently, no more than one site was the subject of intensive research, i.e., the murine aortic sinus, while this site shows no atherosclerosis in humans [for a review see (40)]. This review notes that it is necessary to study more than only one site in the circulation. Of particular interest is the fact that even opposite results can be found at different sites of the artery (41).

As recently reviewed by Meir and Leitersdorf (42), over the past few years apoe $e^{-/-}$mice have been extensively used to examine the effects of nutritional and pharmacological interventions on atherosclerosis. However, a major shortcoming of the apoe $e^{-1-}$ mouse is that the lipoprotein profiles are dissimilar to those in humans, who have most of their cholesterol in LDL particles. Another drawback is that these mice do not have any ApoE, while, as stated earlier, this lipoprotein has many different functions in the organism. This complicates studies and results directed to elucidate the mechanism of lipid metabolism, in particular the mechanisms of drug and dietary action.

A good example of this complication involves statins [for a review see (43)]. Normally these drugs lower cholesterol levels drastically by inhibiting 3hydroxy-3-methylglutaryl-coenzyme A (HMG-CoA) reductase, but in apoe ${ }^{-1-}$ mice, cholesterol levels and plaque area increase upon treatment with this drug (44). Although this phenomenon may seem to be a major disadvantage, it provides a chance to study the effects of statins on plaque formation despite the paradoxical hyperlipidemic effect. This was shown in an interesting study by Bea et al., who reported that simvastatin has a stabilizing effect on atherosclerotic plaques (45).

Another unique feature in the $a p o e^{-/-}$mouse model was observed when these mice received fibrates. These drugs normally cause increased oxidation and decreased hepatic VLDL secretion in wild-type mice by serving as a ligand for the nuclear receptor peroxisome proliferator-activated receptor $\alpha$ (PPAR $\alpha$ ), thereby lowering plasma lipid levels. In apoe ${ }^{-1-}$ mice, however, ciprofibrate and other fibrates caused a three-four-fold increase in plasma cholesterol levels (46). Remarkably, this study concluded that atherosclerotic lesions were also more advanced after fibrate treatment (90 days) than in control animals. These observations are supported by a study using PPAR $\alpha$ /apoe double knock-out mice, in which the PPAR $\alpha$ deficiency resulted in less atherosclerosis than in the apoe $e^{-1-}$ mice (47). However, it was also shown that short-term treatment with a PPAR $\alpha$ ligand can decrease atherosclerosis slightly (48). The lipidincreasing effect of fibrates could be attributed to a fibrate-induced down-regulation of the hepatic scavenger receptor B type I (SRBI) (49). This receptor mediates cholesterol uptake from HDL particles, but was also found to bind $A p o B$, therefore possibly playing a role as backup for VLDL and LDL uptake, and to bind modified LDL $(50,51)$. 


\section{IdIr ${ }^{-/-}$mouse model}

By eliminating the functional gene for LDLR, Ishibashi et al. (31) created a mouse model that displayed mildly elevated cholesterol levels on a diet containing elevated fat and cholesterol levels, but no cholate. A very small part of this cholesterol was confined to the VLDL fraction, but the biggest increase was present in the IDL/LDL fraction (Table 1). Compared to wildtype mice, HDL cholesterol was slightly augmented on a chow diet. In contrast to the wild-type lipoprotein profile, in which most cholesterol is present in the HDL fraction, this profile is more comparable with the human plasma lipoprotein profile, in which cholesterol is mainly confined to the LDL fraction.

Quantification of atherosclerosis showed mild to moderate atherosclerotic lesions in the aortic root and coronary arteries of mice fed a mild atherogenic diet lacking excessive amounts of cholesterol and cholate (20). Despite the rise in plasma cholesterol in these mice, the effect was not as dramatic as expected. This is probably due to the fact that mice, unlike humans, produce approximately $70 \%$ of their liver apoB as the truncated apoB48 form (52). ApoB48 cannot bind the LDLR but, together with ApoE, it does mediate clearance via the LRP (11). Since the LDLR binds LDL via $A p o B 100$, these mice have a rescue pathway through which lipoproteins containing ApoB48 can be taken up. LRP only plays a significant role in the uptake of ApoB48-containing lipoproteins, and not ApoB100 lipoproteins (53). Other papers have also described an important role for additional receptors. The LRP pathway could function as a backup mechanism for the clearance of remnants when the LDLR is genetically deficient (54). Notably, in the absence of both LDLR and LRP, additional routes for the uptake of lipoproteins through the liver exist (55).

As in the case of models involving apoe, $/ \mathrm{d} / \mathrm{r}^{-1-}$ mice have served as a model to study the role of additional genes in atherosclerosis, although to a lesser extent than apoe ${ }^{-1-}$ mice $(35,56)$.

However, Idlr ${ }^{-1-}$ mice are increasingly appreciated, serving as an excellent host for bone marrow transplantation (BMT) experiments (57). Using this technique, mice are depleted of white blood cells (WBCs) by irradiation and are subsequently injected with WBCs isolated from mice carrying a certain (transgenic/knockout) mutation, leading to an organism with WBCs carrying defects not present in the remaining tissues. Since WBCs, and in particular macrophages and T-cells, have an established role in the pathogenesis of atherosclerosis (22), this technology is widely applied. The apoe ${ }^{-1-}$ mouse is a less preferred host for BMT experiments, because the ApoE produced by BMT cells rescue the apoe deficiency, and transplanted mice are no longer susceptible to atherosclerosis (58). Therefore, apoe ${ }^{-1-}$ mice can only be transplanted with apoe-deficient bone marrow, requiring complex breeding schemes. A good example of the use of $l d l r^{-1-}$ mice in BMT experiments is a study in which, unexpectedly, deletion of the nuclear factor (NF)-кB-activator $І_{\kappa} B$ kinase 2 (IKK2) in macrophages caused a significant worsening of atherosclerosis in these mice (59). This could be explained by the observed reduction in the antiinflammatory cytokine interleukin (IL)-10. These data suggest a dual role for NF-кB in inflammation, not only promoting the inflammatory response, but also controlling it.

It should be borne in mind that in the Idlr knock-out mouse model a complete gene was deleted from the genome, which, as with apoe ${ }^{-1-}$ mice, may uncover the role of backup systems such as the LRP pathway. This route can serve as a backup mechanism for lipoprotein clearance in $l d l r^{-1-}$ mice (60), yielding unforeseen side effects.

\section{APOE3Leiden mouse model}

The mouse model expressing the $A P O E 3 L$ gene was created by transgenesis using DNA from one of the human $A P O E 3 L$ carriers to generate the gene construct (28). The transgenic mouse carries a gene construct consisting of the $A P O E 3 L$ gene, the APOC1 gene and a hepatic control element that was found to regulate the expression of both the APOE and APOC1 genes in the liver (61). Although the APOE3L mouse still expresses endogenous ApoE, it exhibits a hyperlipidemic phenotype, which is in line with the dominant manner of inheritance observed in humans (28). Mice over-expressing the APOC1 gene have elevated triglyceride and cholesterol levels [for a review see (62)]. This is mainly due to the impairment of VLDL uptake by both the LDLR and LRP. Consequently, $A P O C 1$ serves to further increase the level of plasma triglycerides (63).

When fed on chow, APOE3L mice showed a small increase in cholesterol levels and a doubling of plasma triglycerides. However, these animals seemed to be very responsive to a high-fat diet containing cholate, displaying an increase in plasma cholesterol levels of approximately 10-fold, mainly in the VLDL fraction. Triglyceride levels decreased to almost half of the value found for mice fed on chow (64) (Table 1). After a period of only 14 days of feeding an atherogenic diet, atherosclerotic plaques were found in these mice at the sinus valves, the carotid arteries and other parts of the aorta. A positive correlation was observed between the lesion area and the serum cholesterol level, indicating that hyperlipidemia is an important determinant in lesion formation (64). However, $A P O E 3 L$ mice were found to be less susceptible to atherosclerosis than the apoe ${ }^{-/-}$mouse (65).

The most valuable property of this model is the excellent response to drugs and diet interventions. In part, this is due to the fact that the main cause of hyperlipidemia in this model is a reduction in VLDL turnover, due to decreased LDLR binding and decreased lipolysis of VLDL. This modification is more subtle than the complete ApoE deficiency in the apoe ${ }^{-1-}$ model.

Importantly, unlike the apoe ${ }^{-1-}$ mouse, the APOE3L mouse shows a hypolipidemic response to known 
lipid-lowering statin drugs, such as lovastatin, and to PPAR $\alpha$ agonists, such as gemfibrozil (32). As previously mentioned, positive correlation was found between the lesion area and serum cholesterol exposure (65), so lipid-lowering using statin treatment significantly retarded the progression of atherosclerotic lesions $(66,67)$. The APOE3L model is therefore an excellent model for testing the hypolipidemic properties of these kinds of drugs.

The effects of dietary fish oil were tested in this hyperlipidemic mouse model (68). In contrast to the apoe ${ }^{-l-}$ mouse, the APOE3L mouse seemed to be highly responsive to this treatment. There was a strong reduction in serum VLDL due to a decrease in hepatic VLDL triglyceride production induced by $n-3$ polyunsaturated fatty acids (PUFAs).

The APOE3L mouse is well suited to study protein function and interaction with other genes. Since this gene is found in humans, the nature of disease can become clearer using these mice. It should be remembered that the mouse apoe gene is still functional. A major disadvantage of these mice is that they have to be fed a cholate-containing atherogenic diet in order to develop a large increase in plasma lipids and atherosclerosis. It has been proved that cholate-containing diets promote inflammation, liver fatty acid and cholesterol changes, and gall stone formation $(24,25,69)$, which makes research of the plaque itself and its development, especially with respect to inflammation, very difficult.

\section{Common APOE alleles in mouse models}

The ApoE2 isoform causes the same phenotype in humans as the ApoE3L isoform does, but in a recessive way, as described earlier in this review. The recessive properties of $A P O E 2$ are also apparent in the mouse. When fed a chow diet, the APOE2 transgenic mouse (APOE2TG) (70) did not show higher cholesterol levels when compared with non-transgenic mice. Moreover, on a high-fat diet these mice did not develop hyperlipidemia. This was due to the presence of endogenous ApoE. However, when expressed at very high levels (more than $50 \mathrm{mg} / \mathrm{dL}$ ), cholesterol levels were $50 \%$ higher (71). When mice were bred on an $a p o e^{-/-}$background, they became severely hyperlipidemic, even when given a chow diet. This is quite remarkable, because in humans only a small percentage of homozygotes develop FD (3). It was proposed that the reduced availability of apoB-100 could be the cause of the pronounced phenotype, making APOE2TG/apoe ${ }^{-1-}$ mice much more dependent on ApoE-mediated lipoprotein clearance via the LDLR.

The APOE2TG mouse was used together with the $A P O E 3 L$ and the apoe ${ }^{-1-}$ mouse models to assess binding of $\beta$-VLDL to HSPG, a process necessary for the LRP-mediated secretion-recapture process for lipoprotein uptake (11). This showed that LpL enhances this process and that ApoE is not an absolute requirement for binding, but results in isoform-dependent increased binding (72). Crossing APOE2TG and
APOE3L mice on an apoe ${ }^{-1-} / d / r^{-/-}$background showed that clearance of ApoE2- and ApoE3L-containing lipoproteins in the absence of the LDLR, and thus via alternative pathways such as LRP, is inefficient (73). This shows the pivotal role of the LDLR for clearance of VLDL remnants.

Models containing the most common human $A P O E$ alleles, i.e., $E 2, E 3$, and $E 4$, have been generated in mice $(29,74,75)$. Using homologous recombination in embryonic stem cells, the mouse apoe gene has been replaced by the human gene. This approach has the advantage that the gene precisely replaces the endogenous apoe gene. Hence, the human ApoE isoform is expressed according to normal physiological regulation.

APOE2 knock-in (APOE2ki) mice show a phenotype very similar to human type III HLP: a two-three-fold elevation in the plasma levels of total cholesterol and triglyceride, confined to the $\beta-\mathrm{VLDL}$ fraction. These mice respond markedly to diets containing mildly elevated levels of fat and cholesterol. An advantage of this mouse model is that no cholate is needed in the diet to obtain severe diet-induced hyperlipidemia and atherosclerosis. Interestingly, the knock-in mice show the full spectrum of atherosclerotic lesions, even on a regular diet (29).

APOE2 knock-in mice show complete penetrance of the type III HLP phenotype. To test whether the ApoB48 hypothesis was correct, this mouse model was used in a study in which ApoB-100 instead of ApoB48 was expressed by deleting the gene responsible for ApoB-100 editing. This study showed that expression of solely ApoB-100 was not sufficient to reverse the hyperlipidemic phenotype, probably because ApoB-48 and ApoB-100 influence lipoprotein metabolism differently (76). These results indicate that the strong phenotype of $A P O E 2 \mathrm{ki}$ mice is not entirely dependent on the difference in $A p o B$ editing. Using this model it should be possible to determine which conditions predispose to the development of type III HLP in humans. Reduced expression of the LDLR could be one of many possible explanations. It was shown that the plasma lipoprotein profile in mice could be ameliorated by over-expression of the human LDLR in APOE2ki mice (77), again suggesting an important role for this receptor, as also shown in the other APOE mouse models (73). The APOE2ki mouse model has not yet been intensively studied, but may prove to be a good mouse model for hyperlipidemia and atherosclerosis. Unlike the apoe $e^{-1-}$ mouse, this mouse model has a lipoprotein profile that mimics type III HLP patients. Another advantage over apoe $e^{-/-}$mice is the responsiveness to fibrates, indicating that this mouse model may also be suitable for drug-testing. Sullivan et al. (74) found large variations in the response to a high-fat diet between male and female APOE2ki mice. However, it is not clear whether these differences are due to the difference in sex or to different administered diets.

APOE3 knock-in mice, expressing the most common human ApoE isoform, and APOE4 knock-in mice show phenotypes similar to each other, although 
Table 2 Application of mouse models of hyperlipidemia and atherosclerosis.

\begin{tabular}{|c|c|c|c|}
\hline & $I d l r^{-/-}$ & apoe ${ }^{-1-}$ & APOE3L \\
\hline \multicolumn{4}{|l|}{ Atherosclerosis } \\
\hline Lipoprotein & ++ & + & ++ \\
\hline Plaque formation & +++ & +++ & +++ \\
\hline Drug intervention & + & $++^{1}$ & ++ \\
\hline Inflammation & ++ & ++ & - \\
\hline \multicolumn{4}{|l|}{ Lipoprotein metabolism } \\
\hline Lipid-lowering drugs & + & - & +++ \\
\hline Nutritional intervention & + & $+^{2}$ & +++ \\
\hline Gene-gene interaction & $++^{3}$ & $++^{3}$ & $++^{3}$ \\
\hline
\end{tabular}

The Table shows the suitability of several discussed mouse models for experimental use in atherosclerotic research, such as the effect of lipoprotein levels and types, inflammation and drug intervention on the formation of atherogenesis, as well as for the study of atherosclerotic plaques. Applicability in the research of lipoprotein metabolism is also assessed, i.e., the effect of lipid-lowering drugs, nutritional intervention and gene-gene interactions. Applicability is shown according to the following legend: +, fair mouse model; ++ , good mouse model; +++ , excellent mouse model; and - , mouse model not suitable. 1 ApoE-independent mechanisms; the effects of drugs can be investigated without considering their lipid-lowering effect.

${ }^{2}$ Except for ApoE-dependent mechanisms, e.g., it was shown that the lipid-lowering effect of some nutritional interventions has no effect in apoe ${ }^{-/-}$mice. ${ }^{3}$ All models are more or less equal; however, sometimes complementary studies are necessary (e.g., knock-out model together with over-expressing transgene) to study the full gene effect.

there are some differences in lipoprotein distribution. Both show lower plasma lipid levels than APOE2ki when fed on a chow diet (75). Combining data from those three models led to the conclusion that differences in ApoE structure alone can be sufficient to cause differences in VLDL metabolism and atherosclerosis risk in mice (75). In animals that overexpress the human LDLR, a remarkable observation was made. It was found that APOE4ki mice with higher LDLR expression showed accumulation of lipoprotein remnant proteins and increased atherosclerosis, despite the higher affinity of this isoform for the LDLR. This could not be found in APOE3ki mice. The postulated explanation is that ApoE4 becomes trapped in the liver due to its high affinity for the LDLR. Hence, newly synthesized lipoproteins cannot acquire the trapped ApoE and it will become deficient in this apolipoprotein, resulting in slower clearance from the plasma $(33,78)$.

Another possible way of manipulating mice genetically to study ApoE function in vivo in mice is by using adenovirus-mediated gene transfer. This technique uses genetically modified adenoviruses to deliver exogenous genes to several tissues in an organism [for reviews see $(78,79)$ ]. Several studies have demonstrated the usefulness of this technique in gaining more insight into lipoprotein metabolism (31). This approach has been effectively used to determine which ApoE-domains are required for cholesterol and triglyceride homeostasis in vivo (80), as well as to investigate the relative importance of this apolipoprotein in remnant clearance and the pathology of type III HLP.

\section{Conclusions and future prospects}

Before setting up an animal experiment, great thought has to be put into the choice of the right mouse model, weighing possible advantages against the disadvantages while keeping the principal aim of the study in mind.
In this review we have demonstrated that mouse models based on two pivotal genes of lipid metabolism, i.e., APOE and $L D L R$, have provided us with models to study the mechanisms of lipid metabolism and atherosclerosis. Table 2 gives an overview of the applicability of each mouse model.

It is particularly useful to use genetically engineered strains as a tool to expose the role of additional genes in atherosclerosis. Genetic combinations can be easily obtained by crossing different transgenic and knockout models. Thus, the models emphasize the polygenetic nature of atherogenesis. At present, many gene-gene combinations have been tested. An overview of these studies has been published $(42,81)$ and falls beyond the scope of this review. In the near future, the emphasis is likely to shift towards combining transgenic models with mouse genetics and genome-wide expression analysis. In each of these areas, progress has recently been made. Dansky et al. used two inbred strains of mice, which were both deficient for the apoe gene. Using these mice that are sensitized for atherosclerosis the authors were able to find several unique QTLs in addition to those already described (82). Taking this a step further, Schadt et al. combined classical genetics with expression studies (83). They found so-called expression QTLs (eQTL) by correlating DNA variations with gene expression levels, tracking down possible causes of differential expression in sequence variations. These studies may unravel unidentified gene-gene interactions, group individuals that are genetically resembled and discover biochemical pathways (84).

A further integration of these approaches will eventually provide us with detailed insight into the complex genetics of CVD.

\section{Acknowledgements}

The authors are supported by the Netherlands Heart Foundation (NHS) (Grant No. 2002B018), and are part of the European Vascular Genomics Network (EVGN, \#LSHM- 
CT-2003-503254). Marten Hofker and Marc van Bilsen are established investigators of the NHS.

\section{References}

1. Lugo-Somolinos A, Sanchez JE. Xanthomas: a marker for hyperlipidemias. Bol Asoc Med P R 2003;95:12-6.

2. Hobbs HH, Brown MS, Goldstein JL. Molecular genetics of the LDL receptor gene in familial hypercholesterolemia. Hum Mutat 1992;1:445-66.

3. Mahley RW, Rall SC Jr. Type III hyperlipoproteinemia (dysbetalipoproteinemia): the role of apolipoprotein $\mathrm{E}$ in normal and abnormal lipoprotein metabolism, 7th ed. New York: McGraw-Hill, 1995.

4. Schaefer EJ, Gregg RE, Ghiselli G, Forte TM, Ordovas JM, Zech LA, et al. Familial apolipoprotein E deficiency. J Clin Invest 1986;78:1206-19.

5. Ji Z, Fazio S, Mahley R. Variable heparan sulfate proteoglycan binding of apolipoprotein $\mathrm{E}$ variants may modulate the expression of type III hyperlipoproteinemia. J Biol Chem 1994;269:13421-8.

6. Brewer HB Jr, Zech LA, Gregg RE, Schwartz D, Schaefer EJ. NIH conference. Type III hyperlipoproteinemia: diagnosis, molecular defects, pathology, and treatment. Ann Intern Med 1983;98:623-40.

7. Shore VG, Shore B. Heterogeneity of human plasma very low density lipoproteins. Separation of species differing in protein components. Biochemistry 1973; 12:502-7.

8. Mahley RW, Innerarity TL, Bersot TP, Lipson A, Margolis S. Alterations in human high-density lipoproteins, with or without increased plasma-cholesterol, induced by diets high in cholesterol. Lancet 1978;2:807-9.

9. Innerarity TL, Mahley RW. Enhanced binding by cultured human fibroblasts of apo-E-containing lipoproteins as compared with low density lipoproteins. Biochemistry 1978;17:1440-7.

10. Ji ZS, Brecht WJ, Miranda RD, Hussain MM, Innerarity $\mathrm{TL}$, Mahley RW. Role of heparan sulfate proteoglycans in the binding and uptake of apolipoprotein E-enriched remnant lipoproteins by cultured cells. J Biol Chem 1993;268:10160-7.

11. Ji ZS, Fazio S, Lee YL, Mahley RW. Secretion-capture role for apolipoprotein $E$ in remnant lipoprotein metabolism involving cell surface heparan sulfate proteoglycans. J Biol Chem 1994;269:2764-72.

12. Huang $Y$, Liu XQ, Rall SC, Jr., Taylor JM, von Eckardstein A, Assmann G, et al. Overexpression and accumulation of apolipoprotein $\mathrm{E}$ as a cause of hypertriglyceridemia. J Biol Chem 1998;273:26388-93.

13. Rensen PC, van Berkel TJ. Apolipoprotein E effectively inhibits lipoprotein lipase-mediated lipolysis of chylomicron-like triglyceride-rich lipid emulsions in vitro and in vivo. J Biol Chem 1996;271:14791-9.

14. Huang Y, Ji ZS, Brecht WJ, Rall SC Jr, Taylor JM, Mahley RW. Overexpression of apolipoprotein E3 in transgenic rabbits causes combined hyperlipidemia by stimulating hepatic VLDL production and impairing VLDL lipolysis. Arterioscler Thromb Vasc Biol 1999;19:2952-9.

15. Mensenkamp AR, Havekes LM, Romijn JA, Kuipers F. Hepatic steatosis and very low density lipoprotein secretion: the involvement of apolipoprotein E. J Hepatol 2001;35:816-22.

16. Huang $Y$, von Eckardstein A, Wu S, Maeda N, Assmann G. A plasma lipoprotein containing only apolipoprotein $\mathrm{E}$ and with gamma mobility on electrophoresis releases cholesterol from cells. Proc Natl Acad Sci USA 1994;91:1834-8.

17. Zhu Y, Bellosta S, Langer C, Bernini F, Pitas RE, Mahley RW, et al. Low-dose expression of a human apolipopro- tein $\mathrm{E}$ transgene in macrophages restores cholesterol efflux capacity of apolipoprotein E-deficient mouse plasma. Proc Natl Acad Sci USA 1998;95:7585-90.

18. Mahley RW, Huang Y, Rall SC Jr. Pathogenesis of type III hyperlipoproteinemia (dysbetalipoproteinemia). Questions, quandaries, and paradoxes. J Lipid Res 1999; 40:1933-49.

19. de Knijff $P$, van den Maagdenberg AM, Stalenhoef AF, Leuven JA, Demacker PN, Kuyt LP, et al. Familial dysbetalipoproteinemia associated with apolipoprotein E3Leiden in an extended multigeneration pedigree. J Clin Invest 1991;88:643-55.

20. Paigen B, Morrow A, Brandon C, Mitchell D, Holmes P. Variation in susceptibility to atherosclerosis among inbred strains of mice. Atherosclerosis 1985;57:65-73.

21. Ross R. Atherosclerosis - an inflammatory disease. $\mathrm{N}$ Engl J Med 1999;340:115-26.

22. Glass CK, Witztum JL. Atherosclerosis: the road ahead. Cell 2001;104:503-16.

23. Breslow JL. Genetic differences in endothelial cells may determine atherosclerosis susceptibility. Circulation 2000;102:5-6.

24. Liao F, Andalibi A, deBeer FC, Fogelman AM, Lusis AJ. Genetic control of inflammatory gene induction and NFkappa B-like transcription factor activation in response to an atherogenic diet in mice. J Clin Invest 1993; 91:2572-9.

25. Vergnes L, Phan J, Strauss M, Tafuri S, Reue K. Cholesterol and cholate components of an atherogenic diet induce distinct stages of hepatic inflammatory gene expression. J Biol Chem 2003;278:42774-84.

26. Plump AS, Smith JD, Hayek T, Aalto-Setala K, Walsh A, Verstuyft JG, et al. Severe hypercholesterolemia and atherosclerosis in apolipoprotein E-deficient mice created by homologous recombination in ES cells. Cell 1992;71:343-53.

27. Zhang SH, Reddick RL, Piedrahita JA, Maeda N. Spontaneous hypercholesterolemia and arterial lesions in mice lacking apolipoprotein E. Science 1992;258:468-71.

28. van den Maagdenberg AM, Hofker MH, Krimpenfort PJ, de Bruijn I, van Vlijmen B, van der Boom H, et al. Transgenic mice carrying the apolipoprotein E3-Leiden gene exhibit hyperlipoproteinemia. J Biol Chem 1993; 268:10540-5.

29. Sullivan PM, Mezdour H, Quarfordt SH, Maeda N. Type III hyperlipoproteinemia and spontaneous atherosclerosis in mice resulting from gene replacement of mouse Apoe with human Apoe*2. J Clin Invest 1998;102:130-5.

30. Zhang SH, Reddick RL, Burkey B, Maeda N. Diet-induced atherosclerosis in mice heterozygous and homozygous for apolipoprotein E gene disruption. J Clin Invest 1994;94:937-45.

31. Ishibashi S, Brown MS, Goldstein JL, Gerard RD, Hammer RE, Herz J. Hypercholesterolemia in low density lipoprotein receptor knockout mice and its reversal by adenovirus-mediated gene delivery. J Clin Invest 1993;92:883-93.

32. van Vlijmen BJ, Pearce NJ, Bergo M, Staels B, Yates JW, Gribble AD, et al. Apolipoprotein $E^{*} 3$-Leiden transgenic mice as a test model for hypolipidaemic drugs. Arzneimittelforschung 1998;48:396-402.

33. Malloy SI, Altenburg MK, Knouff C, Lanningham-Foster L, Parks JS, Maeda N. Harmful effects of increased LDLR expression in mice with human $\mathrm{APOE}^{*} 4$ but not APOE*3. Arterioscler Thromb Vasc Biol 2004;24:91-7.

34. van Ree JH, van den Broek WJ, Dahlmans VE, Groot PH, Vidgeon-Hart M, Frants RR, et al. Diet-induced hypercholesterolemia and atherosclerosis in heterozygous apolipoprotein E-deficient mice. Atherosclerosis 1994; 111:25-37. 
35. Knowles JW, Maeda N. Genetic modifiers of atherosclerosis in mice. Arterioscler Thromb Vasc Biol 2000; 20:2336-45.

36. Smith JD, James D, Dansky HM, Wittkowski KM, Moore $\mathrm{KJ}$, Breslow JL. In silico quantitative trait locus map for atherosclerosis susceptibility in apolipoprotein E-deficient mice. Arterioscler Thromb Vasc Biol 2003; 23:117-22.

37. Smith JD, Dansky HM, Breslow JL. Genetic modifiers of atherosclerosis in mice. Ann NY Acad Sci 2001; 947:247-52 (discussion 252-3).

38. Rosenfeld ME, Polinsky P, Virmani R, Kauser K, Rubanyi G, Schwartz SM. Advanced atherosclerotic lesions in the innominate artery of the ApoE knockout mouse. Arterioscler Thromb Vasc Biol 2000;20:2587-92.

39. Cullen P, Baetta R, Bellosta S, Bernini F, Chinetti G, Cignarella $A$, et al. Rupture of the atherosclerotic plaque: does a good animal model exist? Arterioscler Thromb Vasc Biol 2003;23:535-42.

40. VanderLaan PA, Reardon CA, Getz GS. Site specificity of atherosclerosis: site-selective responses to atherosclerotic modulators. Arterioscler Thromb Vasc Biol 2004;24:12-22.

41. Reardon CA, Blachowicz L, Lukens J, Nissenbaum M, Getz GS. Genetic background selectively influences innominate artery atherosclerosis: immune system deficiency as a probe. Arterioscler Thromb Vasc Biol 2003;23:1449-54.

42. Meir KS, Leitersdorf E. Atherosclerosis in the apolipoprotein E-deficient mouse: a decade of progress. Arterioscler Thromb Vasc Biol 2004;24:1006-14.

43. Maron DJ, Fazio S, Linton MF. Current perspectives on statins. Circulation 2000;101:207-13.

44. Wang YX, Martin-McNulty B, Huw LY, da Cunha V, Post $J$, Hinchman J, et al. Anti-atherosclerotic effect of simvastatin depends on the presence of apolipoprotein $\mathrm{E}$. Atherosclerosis 2002;162:23-31.

45. Bea F, Blessing E, Bennett B, Levitz M, Wallace EP, Rosenfeld ME. Simvastatin promotes atherosclerotic plaque stability in apoE-deficient mice independently of lipid lowering. Arterioscler Thromb Vasc Biol 2002;22:1832-7.

46. Fu T, Kashireddy $\mathrm{P}$, Borensztajn J. The peroxisome-proliferator-activated receptor alpha agonist ciprofibrate severely aggravates hypercholesterolaemia and accelerates the development of atherosclerosis in mice lacking apolipoprotein E. Biochem J 2003;373:941-7.

47. Tordjman K, Bernal-Mizrachi C, Zemany L, Weng S, Feng $C$, Zhang $F$, et al. PPARalpha deficiency reduces insulin resistance and atherosclerosis in apoE-null mice. J Clin Invest 2001;107:1025-34.

48. Zuckerman SH, Kauffman RF, Evans GF. Peroxisome proliferator-activated receptor alpha,gamma coagonist LY465608 inhibits macrophage activation and atherosclerosis in apolipoprotein $\mathrm{E}$ knockout mice. Lipids 2002;37:487-94.

49. Fu T, Kozarsky KF, Borensztajn J. Overexpression of SR$\mathrm{BI}$ by adenoviral vector reverses the fibrate-induced hypercholesterolemia of apolipoprotein E-deficient mice. J Biol Chem 2003;278:52559-63.

50. Tai ES, Adiconis X, Ordovas JM, Carmena-Ramon R, Real J, Corella D, et al. Polymorphisms at the SRBI locus are associated with lipoprotein levels in subjects with heterozygous familial hypercholesterolemia. Clin Genet 2003;63:53-8.

51. Acton S, Rigotti A, Landschulz KT, Xu S, Hobbs HH, Krieger $\mathrm{M}$. Identification of scavenger receptor SR-BI as a high density lipoprotein receptor. Science 1996; 271:518-20.

52. Greeve J, Altkemper I, Dieterich JH, Greten H, Windler E. Apolipoprotein B mRNA editing in 12 different mammalian species: hepatic expression is reflected in low concentrations of apoB-containing plasma lipoproteins. J Lipid Res 1993;34:1367-83.

53. Veniant MM, Zlot $\mathrm{CH}$, Walzem RL, Pierotti V, Driscoll R, Dichek $D$, et al. Lipoprotein clearance mechanisms in LDL receptor-deficient "Apo-B48-only" and "Apo-B100only" mice. J Clin Invest 1998;102:1559-68.

54. Jong MC, Dahlmans VE, van Gorp PJ, van Dijk KW, Breuer $\mathrm{ML}$, Hofker $\mathrm{MH}$, et al. In the absence of the low density lipoprotein receptor, human apolipoprotein C1 overexpression in transgenic mice inhibits the hepatic uptake of very low density lipoproteins via a receptor-associated protein-sensitive pathway. J Clin Invest 1996; 98:2259-67.

55. Mahley RW, Ji Z-S. Remnant lipoprotein metabolism: key pathways involving cell-surface heparan sulfate proteoglycans and apolipoprotein E. J Lipid Res 1999; 40:1-16.

56. Daugherty A. Mouse models of atherosclerosis. Am J Med Sci 2002;323:3-10.

57. de Winther MP, Heeringa P. Bone marrow transplantations to study gene function in hematopoietic cells. Methods Mol Biol 2003;209:281-92.

58. Fazio S, Babaev VR, Burleigh ME, Major AS, Hasty $A H$, Linton MF. Physiological expression of macrophage apoE in the artery wall reduces atherosclerosis in severeIy hyperlipidemic mice. J Lipid Res 2002;43:1602-9.

59. Kanters E, Pasparakis M, Gijbels MJ, Vergouwe MN, Partouns-Hendriks I, Fijneman RJ, et al. Inhibition of NF-kappaB activation in macrophages increases atherosclerosis in LDL receptor-deficient mice. J Clin Invest 2003;112:1176-85.

60. Jong MC, Dahlmans VE, van Gorp PJ, van Dijk KW, Breuer $\mathrm{ML}$, Hofker $\mathrm{MH}$, et al. In the absence of the low density lipoprotein receptor, human apolipoprotein C1 overexpression in transgenic mice inhibits the hepatic uptake of very low density lipoproteins via a receptor-associated protein-sensitive pathway. J Clin Invest 1996;98: 2259-67.

61. Shachter NS, Zhu Y, Walsh A, Breslow JL, Smith JD. Localization of a liver-specific enhancer in the apolipoprotein E/C-I/C-II gene locus. J Lipid Res 1993; 34:1699-707.

62. Jong MC, Hofker MH, Havekes LM. Role of ApoCs in lipoprotein metabolism: functional differences between ApoC1, ApoC2, and ApoC3. Arterioscler Thromb Vasc Biol 1999;19:472-84.

63. Jong MC, Dahlmans VE, van Gorp PJ, Breuer ML, Mol MJ, van der Zee $A$, et al. Both lipolysis and hepatic uptake of VLDL are impaired in transgenic mice coexpressing human apolipoprotein $E^{*} 3$ Leiden and human apolipoprotein C1. Arterioscler Thromb Vasc Biol 1996;16:934-40.

64. van Vlijmen BJ, van den Maagdenberg AM, Gijbels MJ, van der Boom $\mathrm{H}$, HogenEsch $\mathrm{H}$, Frants RR, et al. Dietinduced hyperlipoproteinemia and atherosclerosis in apolipoprotein E3-Leiden transgenic mice. J Clin Invest 1994:93:1403-10.

65. Groot $\mathrm{PH}$, van Vlijmen BJ, Benson GM, Hofker $\mathrm{MH}_{\text {, }}$ Schiffelers R, Vidgeon-Hart M, et al. Quantitative assessment of aortic atherosclerosis in APOE*3 Leiden transgenic mice and its relationship to serum cholesterol exposure. Arterioscler Thromb Vasc Biol 1996; 16:926-33.

66. van de Poll SW, Delsing DJ, Jukema JW, Princen HM, Havekes LM, Puppels GJ, et al. Raman spectroscopic investigation of atorvastatin, amlodipine, and both on atherosclerotic plaque development in $\mathrm{APOE}^{*} 3$ Leiden transgenic mice. Atherosclerosis 2002;164:65-71.

67. van de Poll SW, Delsing DJ, Wouter Jukema J, Princen HM, Havekes LM, Puppels GJ, et al. Effects of amlodipine, atorvastatin and combination of both on advanced 
atherosclerotic plaque in $\mathrm{APOE}^{*} 3$-Leiden transgenic mice. J Mol Cell Cardiol 2003;35:109-18.

68. van Vlijmen BJ, Mensink RP, van't Hof HB, Offermans RF, Hofker MH, Havekes LM. Effects of dietary fish oil on serum lipids and VLDL kinetics in hyperlipidemic apolipoprotein $E^{*} 3$-Leiden transgenic mice. J Lipid Res 1998;39:1181-8.

69. Bergman F, Juul AH, Van der Linden W. Development and regression of morphological and biochemical changes in hamsters and mice fed a cholesterol cholic acid containing diet. Acta Pathol Microbiol Scand A 1970;78:179-91.

70. van Vlijmen BJ, van Dijk KW, van't Hof HB, van Gorp PJ, van der Zee $A$, van der Boom $H$, et al. In the absence of endogenous mouse apolipoprotein $E$, apolipoprotein $E * 2$ (Arg-158 $\rightarrow$ Cys) transgenic mice develop more severe hyperlipoproteinemia than apolipoprotein $E^{*} 3-$ Leiden transgenic mice. J Biol Chem 1996;271: 30595-602.

71. Huang Y, Schwendner SW, Rall SC Jr, Mahley RW. Hypolipidemic and hyperlipidemic phenotypes in transgenic mice expressing human apolipoprotein E2. J Biol Chem 1996;271:29146-51.

72. de Beer F, Hendriks WL, van Vark LC, Kamerling SW, van Dijk KW, Hofker $\mathrm{MH}$, et al. Binding of $\beta$-VLDL to heparan sulfate proteoglycans requires lipoprotein lipase, whereas ApoE only modulates binding affinity. Arterioscler Thromb Vasc Biol 1999;19:633-7.

73. van Dijk KW, van Vlijmen BJ, de Winther MP, van't Hof $B$, van der Zee $A$, van der Boom $\mathrm{H}$, et al. Hyperlipidemia of ApoE2(Arg(158)-Cys) and ApoE3-Leiden transgenic mice is modulated predominantly by LDL receptor expression. Arterioscler Thromb Vasc Biol 1999; 19:2945-51.

74. Sullivan PM, Mezdour H, Aratani Y, Knouff C, Najib J, Reddick $R L$, et al. Targeted replacement of the mouse apolipoprotein $\mathrm{E}$ gene with the common human APOE3 allele enhances diet-induced hypercholesterolemia and atherosclerosis. J Biol Chem 1997;272:17972-80.

75. Knouff C, Hinsdale ME, Mezdour H, Altenburg MK, Watanabe M, Quarfordt SH, et al. Apo E structure determines
VLDL clearance and atherosclerosis risk in mice. J Clin Invest 1999;103:1579-86.

76. Hinsdale ME, Sullivan PM, Mezdour H, Maeda N. ApoB48 and apoB-100 differentially influence the expression of type-III hyperlipoproteinemia in APOE*2 mice. J Lipid Res 2002;43:1520-8.

77. Knouff C, Malloy S, Wilder J, Altenburg MK, Maeda N. Doubling expression of the low density lipoprotein receptor by truncation of the $3^{\prime}$-untranslated region sequence ameliorates type III hyperlipoproteinemia in mice expressing the human ApoE2 isoform. J Biol Chem 2001;276:3856-62.

78. Havel RJ, Hamilton RL. Hepatic catabolism of remnant lipoproteins: where the action is. Arterioscler Thromb Vasc Biol 2004;24:213-5.

79. Zannis VI, Chroni A, Kypreos KE, Kan HY, Cesar TB, Zanni EE, et al. Probing the pathways of chylomicron and HDL metabolism using adenovirus-mediated gene transfer. Curr Opin Lipidol 2004;15:151-66.

80. Kypreos KE, van Dijk KW, van Der Zee A, Havekes LM, Zannis VI. Domains of apolipoprotein E contributing to triglyceride and cholesterol homeostasis in vivo. Carboxyl-terminal region 203-299 promotes hepatic very low density lipoprotein-triglyceride secretion. J Biol Chem 2001;276:19778-86.

81. Veniant MM, Withycombe S, Young SG. Lipoprotein size and atherosclerosis susceptibility in Apoe And $^{-1-}$ and $\mathrm{Ldr}^{-/-}$ mice. Arterioscler Thromb Vasc Biol 2001;21:1567-70.

82. Dansky HM, Shu P, Donavan M, Montagno J, Nagle DL, Smutko JS, et al. A phenotype-sensitizing Apoe-deficient genetic background reveals novel atherosclerosis predisposition loci in the mouse. Genetics 2002; 160:1599-608.

83. Schadt EE, Monks SA, Drake TA, Lusis AJ, Che N, Colinayo $V$, et al. Genetics of gene expression surveyed in maize, mouse and man. Nature 2003;422:297-302.

84. Darvasi A. Genomics: gene expression meets genetics. Nature 2003;422:269-70.

Received November 12, 2004, accepted February 4, 2005 